Clearly in certain circumstances treatment with betamethasone may be very beneficial and the benefits may outweigh the short-term risks. Of long-term risks we know nothing, but the record of perinatal medicine in this respect is not reassuring -with deafness, blindness, and cancer among the side effects of treatment used in good faith and for good reasons in various conditions from threatened abortion to early infection. Certainly in the fetus steroids play a major part in ordering normal development, and there is not only the problem of their action before birth but their suppression afterwards to consider. ${ }^{26}$ Meanwhile, a high standard of care in the antenatal clinic and at birth is the best way of ensuring a low mortality from respiratory distress rather than the general introduction of either betamethasone prophylaxis or of intensive care of affected infants, which is most economic when centralised in referral units.

1 Roberton, N C, and Tizard, J P M, British Medical fournal, 1975, 3, 271.

2 Prod'hom, L S, et al, Pediatrics, 1974, 53, 170.

${ }^{3}$ Chamberlain, R, British Births, 1970, vol 1, p 238. London, Heinemann, 1975.

${ }^{4}$ Dinwiddie, R, et al, Archives of Disease in Childhood, 1974, 49, 703.

5 Stocks, J, and Godfrey, S, Pediatrics, 1976, 57, 352

${ }^{6}$ Lynch, M, Lancet, 1975, 2, 317.

7 DHSS, Health and Personal Social Service Statistics for England, 1975, p 131. London, HMSO, 1976.

${ }^{8}$ Fanaroff, A, et al, Year Book of Pediatrics 1976, ed S Gellis, p 7. Chicago, Year Book Medical Publishers, 1976.

${ }^{9}$ Liggins, C G, in Foetal Autonomy, (CIBA Foundation Symposium) ed G E W Wolstenholme and M O'Connor, p 218. London, Churchill, 1969.

10 Gluck, L, et al, Pecïatric Research, 1972, 6, 81.

${ }_{11}$ Schirar, A, et al, American fournal of Obstetrics and Gynecology, 1975, 121, 653.

12 Sproule, W B, Greene, M E, and Whitfield, C R, American fournal of Obstetrics and Gynecology, 1974, 119, 653.

13 Rokos, J, et al, Pediatrics, 1968, 42, 204.

14 Pearson, R, Lancet, 1976, 1, 60.

15 Omer, M A, Robson, E, and Neligan, G A, Archives of Diseases in Childhood, 1974, 49, 219.

${ }^{16}$ James, L S, New England fournal of Medicine, 1975, 292, 1291.

17 Chiswick, M, Archives of Disease in Childhood, 1976, in press.

18 Boughton, K, Gandy, G, and Gairdner, D, Archives of Disease in Childhood, 1970, 45, 311 .

19 Smith, B T, et al, fournal of Pediatrics, 1975, 87, 953

${ }^{20}$ Raiha, N C P, and Edkinse, E, Communication to E S P R, Rotterdam, 1976.

${ }^{21}$ Sparks, J W, Lynch, A, and Glinsmann, W, Pediatric Research, 1976, 10, 415.

${ }^{22}$ Liggins, G C, and Howie, R N, Pediatrics, 1972, 50, 515.

23 Warrell, D W, and Taylor, R E, Lancet, 1968, 1, 117

24 Fargier, P, et al, Novvelle Presse Médicale, 1974, 3, 1595.

${ }_{25}$ Nathan, D M, Mount Sinai fournal of Medicine, New York, 1975, 42, 150.

26 Osathanondh, R, et al, Pediatric Research, 1976, 10, 342.

\section{The fetal alcohol syndrome}

Alcohol drunk in excess by expectant mothers is a powerful cause of growth retardation and congenital malformations. The evidence for this statement comes from anecdotal clinical reports ${ }^{1-6}$ and from animal experiments. ${ }^{78}$ So far, though, we have no evidence that social drinking constitutes any risk to the fetus: all the women concerned have been heavy drinkers before and during their pregnancies. In some cases they had complications of alcoholism such as cirrhosis, anaemia, chronic undernutrition, and delirium tremens, ${ }^{2356}$ and some were in an alcoholic stupor at the time of delivery. ${ }^{26}$ Generally they came from the lower socioeconomic groups, were multiparous, and in their late 20 s or older.

Maternal alcoholism seems to produce a definite fetal syndrome with features which, though not unique, should arouse suspicion. In most accounts 256 the affected children have had maxillary hypoplasia, with prominence of the forehead and lower jaw, short palpebral fissures, small eyes and epicanthic folds, and in some cases a squint or unilateral ptosis. There is severe intrauterine growth retardation. The infants are both short and light for dates, and the growth potential in childhood is poor. Almost all children have had microcephaly and mental retardation and some infants have had obvious tremulousness, not responding to sedation, and persisting into childhood with incoordination and poor gross motor performance. ${ }^{2}$ Many children were investigated in hospital or placed with foster parents because of failure to thrive, but none of these showed any real improvement in growth or mental development. ${ }^{25}$

There is some variety in the other anomalies that occur. Congenital heart disease including ventricular septal defect is common, while skin capillary haemangiomata, deficient upper helices of the ears, low set ears, dislocation of the hips, restriction of movement of some joints, abnormal palmar creases, overlapping of the fingers, and (in two cases) hirsutism ${ }^{4}$ have all been reported. In the early descriptions the authors considered the possibility of other syndromes before they diagnosed the fetal alcohol syndrome. Thus one of the patients reported by Jones and $\mathrm{Smith}^{3}$ was originally thought to have the Cornelia de Lange and the other the trisomy-18 syndrome, and the patient reported by Hall and Orenstein ${ }^{9}$ was thought to have Noonan's syndrome. Possibly other patients may not yet have been correctly diagnosed.

Circumstantial evidence for the adverse effects of maternal alcoholism seems to have existed for some time, ${ }^{3}$ but confirmation has been slow. Perhaps this is because the incidence of maternal alcoholism is itself low: in the report of Jones et al ${ }^{4}$ only 23 women out of 55000 mothers were regarded as definitely alcoholic. Nevertheless, the incidence seems variable: out of 1594 pregnant women in a poor urban population reviewed by Ulleland, 12 were alcoholic. ${ }^{1}$ The risk of fetal death and malformation seems high. Of 23 babies, four died, and the 13 offspring were smaller than controls and six had malformations typical of the fetal alcohol syndrome. ${ }^{4}$ Ten of the 12 infants reported by Ulleland ${ }^{2}$ were undersized. This high incidence of damage has been further confirmed by Shruygin's study, ${ }^{10}$ in which over half the children born to alcoholic mothers were mentally retarded.

Of great practical clinical importance are those children who might be partially affected ${ }^{2}$ and who may not be recognised until a more severely affected sibling is born. Certainly more than one child in a family may be affected. One patient, whose mental retardation was attributed to asphyxia, ${ }^{6}$ was not recognised as suffering from maternal alcoholism until his younger brother was born. Re-examination showed a convergent squint, some limitation of joint mobility, and short palpebral fissures. In another instance a younger sibling from a different father was also found to be affected, ${ }^{3}$ and. Palmer et $a l^{5}$ reported a family of four children of whom three were affected. Clearly recognition of the syndrome may prevent recurrence, though, even when suspected, alcoholism may be difficult to confirm ${ }^{14}$ and to treat.

Evidence from animal studies of the teratogenic effects of alcohol is growing, though an early report by Papara-Nicholson and Telford ${ }^{7}$ of the production of low birthweight litters in guinea-pigs was not confirmed in the rabbit. ${ }^{11}$ Chernoff, ${ }^{8}$ however, has now reported embryo resorption and low birthweight fetuses with skeletal, eye, cardiovascular, and central nervous defects in pregnant mice fed high-alcohol diets.

Other factors are associated with this syndrome-in particular heavy smoking by the mothers, poor maternal nutrition, 
poverty, and infrequent clinic attendances. There is, however, no evidence that these associated factors can produce the full syndrome, ${ }^{12} 13$ and it must be accepted that alcohol is the prime teratogen. Clearly the risk is that alcoholism may be overlooked and the low birthweight and failure to thrive incorrectly attributed to other adverse medicosocial factors.

${ }^{1}$ Ulleland, C N, Annals of the New York Academy of Sciences, 1972, 197, 167.

2 Jones, K L, et al, Lancet, 1973, 1, 1267.

3 Jones, K L, and Smith, D W, Lancet, 1973, 2, 999.

4 Jones, K L, et al, Lancet, 1974, 1, 1076.

Palmer, R H, et al, Pediatrics, 1974, 53, 490.

Mulvihill, J J, et al, American fournal of Obstetrics and Gynecology, 1976, 125, 937.

7 Papara-Nicholson, D, and Telford, I R, Anatomical Record, 1957, 127, 438.

${ }^{8}$ Chernoff, G F, Teratology, 1975, 11, 14A.

${ }^{9}$ Hall, B D, and Orenstein, W A, Lancet, 1974, 1, 680.

10 Shurygin, G I, Pediatriya (Moscow), 1974, no 11, 71 .

11 Giroud, A, and Tuchmann-Duplessis, H, Pathologie et Biologie, 1962, 10, 141

12 Ounsted, M, and Ounsted, C, On fetal growth rate. Clinics in Developmental Medicine, No 46. London, Heinemann, 1973.

${ }^{13}$ Butler, N R, and Alderman, E D (eds), Perinatal Problems. London, Livingstone, 1969

\section{Contraceptive dynamism}

There is no ideal contraceptive. Every women leading an active sexual life necessarily has to incur the risks of her chosen contraceptive's particular shortcomings and of an unplanned pregnancy should the method let her down. During her reproductive lifetime she is likely to have varying needs for contraception; the relevant factors include the permanence or otherwise of her sexual relationship, her own career, her desire for children, and whether she wishes to retain her potential for reproduction. It is a truism that those methods which have the least side effects are the most inconvenient and are related to intercourse, while the easiest ways of achieving continued protection against pregnancy require a profound systemic modification of the woman's endocrine function or have the hazards of local trauma to the genital tract. Right at the end of the spectrum is the ultimate deterrent: permanent interruption of the pathway for the gametes in one or other partner.

In our present society with its acceptance of premarital intercourse the doctor should be able to provide advice on contraception without moralising or judging the case. Yet studies on unmarried women in Britain ${ }^{1}$ and the $\mathrm{USA}^{2}$ clearly indicate that many women at risk of unplanned pregnancy do not use contraception. Even among university students for whom special efforts were made in sex education correct contraceptive usage left much to be desired. ${ }^{34}$ Further ways of improving these educative measures and their impact are urgently required. In this group, where spontaneous and occasional intercourse most frequently occurs, the condom is often used. ${ }^{1}$ Its effectiveness could be extended by improved availability, greater care in its use, and the use of adjunct compatible spermicides. Indeed, the condom remains the most common method used by married couples in Britain, especially those married before $1965 .^{1}$ The reliability of the sheath in selected groups is far higher, ${ }^{5}$ especially when impregnated with spermicides, ${ }^{6}$ than the figures usually quoted, ${ }^{7}$ and for many individuals its freedom from systemic and local side effects makes the method highly acceptable. Nevertheless, for high effectiveness to be maintained constant care and attention are required each time the method is used.
Similarly, for couples who prefer the woman to use a mechanically occlusive method the diaphragm in a selected family planning population may have a high degree of acceptability and reliability. ${ }^{8}$ In a recent detailed study of the long term follow-up of women using different methods of contraception Vessey et al ${ }^{9}$ pointed out that there are "no material side effects associated with the use of the diaphragm apart from the risk of pregnancy and that there may be some unintended benefits." Indeed, they found that users of the diaphragm tended to persist more with the method, and that a high percentage continued with it. Nevertheless, for many couples the constraints of a diaphragm may be too restrictive for satisfactory sexual relationships.

Women using oral contraceptives or an intrauterine device (IUD) pay a price for their convenience. With the former, despite the exclusion of women with a past history, there remains an increased risk of thromboembolism. ${ }^{9}$ In particular, the hazards of myocardial infarction increase dramatically in those over $35 .{ }^{10}$ This is the age group, too, where in spite of recent improvements maternal mortality remains far higher than that of younger women. ${ }^{11}$ Furthermore, the incidence of gall bladder disease is increased, with the attendant problems of surgical intervention. ${ }^{912}$ Another point highlighted by Vessey's study is the clear evidence of some temporary impairment of fertility after discontinuing oral contraception. ${ }^{9}$ On the credit side, however, besides the spontaneity allowed by the method, is the extremely low incidence of these adverse effects and the decrease in incidence of benign tumours of the breast. $^{13}$

Women who use an IUD have more hospital referrals for anaemia and salpingitis ${ }^{9}$-not surprisingly, since menstrual disturbances are a recognised complication of the IUD. ${ }^{14}$ Furthermore, clearly the risk of developing pelvic sepsis is significantly increased for users of IUDs. ${ }^{15}$ The role of the cervical appendage, the shape and size of the IUD, and the effect of an incorporated pharmacologically active agent (trace element or steroid) in the genesis of these problems remain to be determined. These factors may well partly explain the remarkably unfavourable outcome of unplanned pregnancy in IUD users, both in terms of ectopic gestation and of miscarriage. ${ }^{9}$

Age and fashion both have their effects, and doctors should remember to ask about the contraceptive practice of their patients in order to keep the options under review. Difficulties and tensions in contraceptive usage may arise in a couple and may present in a variety of ways. Not only will the type of contraceptive used by a particular couple undergo a series of changes through their reproductive lifetime, but their need for relative effectiveness will alter depending on their frequency of sexual intercourse and the possible impact of an unplanned pregnancy on them. For the youngster for whom sexual intercourse is frequently unpremeditated and often unexpected the sheath (preferably reinforced with a spermicide) should be readily available and has the added bonus of protection against sexually transmitted diseases. Once a sexual relationship has been established the doctor should be able to discuss the relative merits and disadvantages of the various options open to the couple. For the young couple maximal effectiveness is often essential: a well-chosen combined oral contraceptive has little risk and has the added advantage of precise cycle control, relief of spasmodic dysmenorrhoea, and lessened menstrual flow. A small copper IUD might be considered in women intolerant of the pill, but the IUD is probably more appropriate for the parous woman who is spacing her family. For those couples who are prepared to make the effort the mech- 